\title{
PAUTAS DEONTOLÓGICAS PARA EL PERIODISMO DIGITAL
}

\author{
Deontological guidelines for digital journalism
}

\author{
Jesús Cruz-Álvarez y Juan-Carlos Suárez-Villegas
}
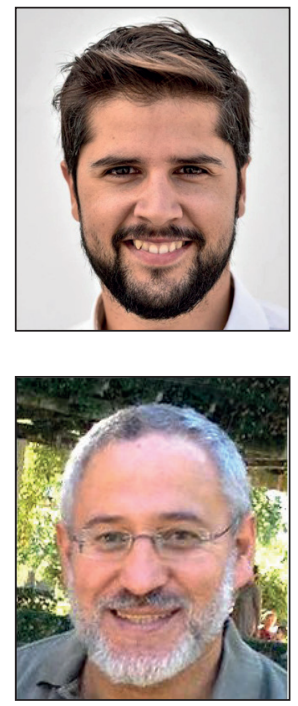

Jesús Cruz-Álvarez, licenciado en Periodismo y doctor en Comunicación por la Universidad de Sevilla, es investigador en periodismo digital y los dilemas éticos planteados por el ejercicio de la profesión en el nuevo entorno de internet. Coordinador del IV Congreso internacional de ética de la comunicación. Miembro investigador del proyecto Desafíos éticos en el periodismo digital. Análisis comparativo entre cinco países europeos.

http://orcid.org/0000-0003-3928-7013

jcruz12@us.es

Juan-Carlos Suárez-Villegas es catedrático de la Universidad de Sevilla en el Departamento de Metafísica y Corrientes Actuales de la Filosofía, Ética y Filosofía Política. Es director del grupo de investigación Pensamiento Crítico, Comunicación y Derechos Humanos. Imparte la asignatura Ética y deontología periodística en la Facultad de Comunicación de la Universidad de Sevilla. Director del Congreso internacional de ética de la comunicación (2011, 2013, 2015 y 2017) y director del proyecto Desafíos éticos en el periodismo digital. Análisis comparativo entre cinco países europeos. http://orcid.org/0000-0002-2199-7098

jcsuarez@us.es

Universidad de Sevilla. Facultad de Comunicación Av. Américo Vespucio, s/n. 41092 Sevilla, España

\section{Resumen}

La tendencia a la instantaneidad informativa, debida en parte a la irrupción de las redes sociales en el discurso periodístico, incide de forma directa en la calidad del ejercicio profesional y en la consideración ética del mismo. A este fenómeno, e íntimamente relacionado con él, cabría añadir la participación de las audiencias en la configuración de las noticias, planteando nuevos retos a la profesión que precisan de medidas y habilidades que no siempre pueden ser buscadas en los códigos deontológicos clásicos. Se precisan por tanto nuevos principios que guíen la práctica diaria. En este artículo se propone un decálogo de pautas deontológicas aplicables a la labor profesional en el periodismo digital.

\section{Palabras clave}

Deontología; Periodismo digital; Participación; Instantaneidad; Redes sociales; Periodistas; Web 2.0; Comunicación; Internet; Cultura participativa.

\section{Abstract}

The tendency towards the instantaneity of information, due in part to the irruption of social networks into journalistic discourse, has had a direct impact on the quality and ethical considerations of professional practice. Closely related to this phenomenon is the participation of the audiences in configuring the news, posing new challenges to the profession that require measures and skills that cannot always be sought in classic codes of ethics. New principles are, therefore, needed to guide daily practice. In this article a decalogue of deontological guidelines applicable to professional work in digital journalism is proposed.

\section{Keywords}

Deontology; Digital journalism; Participation; Immediacy; Social networks; Journalists; Web 2.0; Communication; Internet; Participatory culture.

Cruz-Álvarez, Jesús; Suárez-Villegas, Juan-Carlos (2017). "Pautas deontológicas para el periodismo digital". El profesional de la información, v. 26, n. 2, pp. 249-254. 


\section{Introducción}

Las características inherentes a la comunicación digital han afectado de manera determinante al modo de hacer y entender el periodismo: la interactividad de los productos digitales, su estructura hipertextual, la multimedialidad o la actualización constante de los contenidos, explican la naturaleza versátil, descentralizada y relativamente horizontal del nuevo entorno comunicativo. Estas características dan forma a procesos de convergencia en los ámbitos tecnológico, económico, mediático, político o social, de acuerdo a una lógica de retroalimentación constante entre ellos.

El resultado es un escenario radicalmente diferente al tradicional, en el que el periodismo se ejercía desde una clara posición de autoridad frente a un público masivo y marcado por cierta pasividad. Entre otras razones, este escenario ha cambiado a raíz de la adopción de nuevos roles comunicativos por parte del público.

El cambio radical de los procesos del periodismo digital y la multiplicación de los actores implicados demanda un nuevo enfoque deontológico para guiar la práctica profesional

De hecho, ya ni siquiera podemos hablar de público a modo de etiqueta conceptual homogénea, sino de usuarios (Lievrouw; Livingstone, 2002), un calificativo más acorde a la heterogeneidad de su naturaleza. Bruns (2005) llegó a proponer incluso el concepto de produser (o prosumidor), destacando la naturaleza ambivalente de receptor y creador de contenidos presente en este nuevo participante de la comunicación digital. Esto es fruto del fenómeno denominado por Castells (2008) como "autocomunicación de masas", es decir, la individualización del consumo y producción de comunicación en el entorno digital.

Ante esta realidad no es difícil concluir que el periodismo actual se parece poco al tradicional. Los periodistas ya no sólo se ocupan de recabar la información, editarla y publicarla, lo cual no era precisamente un proceso exento de dificultad, sino que ahora deben hacerlo en un entorno donde las fuentes e inputs informativos se multiplican, donde es preciso interaccionar con esas redes, en una vorágine inabarcable de información.

Si anteriormente los problemas deontológicos derivados de la práctica periodística eran una cuestión importante para la consideración social de la profesión, no cabe duda de que hoy día es un elemento capital sin el cual dicha profesión vería comprometida su supervivencia. El periodismo, en un momento en el que cualquier usuario puede convertirse en un improvisado medio de comunicación, debe surgir como la legítima correa de transmisión entre los ciudadanos y los elementos de poder, haciendo especial hincapié en los códigos deontológicos que corroboran un ejercicio veraz, riguroso y honesto de la comunicación.

Ahora bien, ¿deben ser esos códigos deontológicos los mismos que han regido hasta ahora a la profesión? ¿Deben ser actualizados o incluso remodelados a partir de las nuevas características del entorno digital? En el presente artículo indagaremos en la conveniencia de establecer una serie de pautas deontológicas específicamente destinadas a regular el periodismo digital.

\section{Nuevos retos, ¿nuevas soluciones?}

Buena parte de los dilemas éticos tradicionales que ha afrontado la profesión y que han derivado en una pérdida de credibilidad frente a los ciudadanos, están relacionados con una escasa rigurosidad en el cumplimiento de alguno o varios de los mecanismos de verificación, independencia, interés y responsabilidad. Podríamos aseverar que también los problemas éticos auspiciados por el entorno digital están íntimamente ligados con estos mecanismos para alcanzar la verdad periodística, a pesar de que las condiciones de trabajo y las relaciones mantenidas con la tecnología y la sociedad sean sustancialmente diferentes.

Esa relación con la sociedad marca gran parte de las condiciones en las que se desenvuelve el periodismo digital, y se concreta en el afán participativo demostrado por los usuarios en el proceso informativo (Said-Hung, 2010). Éste es probablemente el gran cambio sufrido por la profesión, pues va más allá de una mera actualización tecnológica basada en herramientas y soportes novedosos. La involucración de los ciudadanos en las distintas etapas informativas altera los hábitos de consumo, de producción y hasta el modo de relación social (Purcell et al., 2010). Por lo tanto, si bien es cierto que el compromiso de la profesión con la verdad y los roles y valores periodísticos tradicionales desplegados para alcanzarla continúan siendo prioritarios, es preciso considerar la importancia de una gestión responsable y ética de las comunidades creadas en torno a los medios y sus modos de participación. Al fin y al cabo, éstas también influyen de forma determinante en el resultado definitivo del proceso informativo y su búsqueda de la verdad.

Es decir, tal y como apunta Deuze (2008, p. 276), internet:

"da forma y redefine una serie de cuestiones éticas y morales a las que tienen que hacer frente los periodistas cuando trabajan en el entorno online o emplean fuentes que han encontrado en la Red"

Hayes, Singer y Ceppos (2007, p. 275), sostienen que en el nuevo ecosistema digital, "ya no es posible aceptar de modo indefinido e incondicional los presupuestos tradicionales sobre los roles y los valores periodísticos" sino que se deben aplicar otras guías éticas que atajen retos que antes no existían, entre ellos el de la participación de los usuarios en la construcción de la noticia.

En el informe presentado por Anderson, Bell y Shirky (2012) para el Tow Center también se hacía hincapié en las posibilidades del nuevo entorno, como la colaboración con los usuarios, las herramientas de análisis de datos, o el uso de algoritmos para conformar un proceso periodístico más transparente (Diakopoulos; Koliska, 2016).

Singer (2008) afirma que los principios éticos que guían al periodismo en la Web deben ser los mismos que aquellos que hacen lo propio con el periodismo tradicional, aunque 
reconoce que deben ser reformulados sus fundamentos teóricos en la medida en que el rol social del periodista ha cambiado. Por ejemplo, el concepto de independencia no es el mismo en el sistema mediático clásico, donde la estructura empresarial y sus relaciones con el contexto político-económico marcan su cumplimiento, que en el digital, en el que la responsabilidad recae en mayor medida en el periodista debido a su mayor exposición y contacto con las audiencias.

\section{Los medios de comunicación y sus pro- fesionales se enfrentan al ecosistema digital sin unas guías claras de cómo ges- tionar la nueva realidad}

Ya en un trabajo de 1998 organizado por la American Society of Newspaper Editors (ASNE) y el Poynter Institute (Mitchell; Mann, 2002), se señalaban los cinco grandes bloques que debían abordar los códigos deontológicos en el entorno que en ese momento se estaba desarrollando. Lo curioso es que tres de esos cinco bloques, entre los que también se incluían las presiones comerciales y el uso de las bases de datos, guardaban una estrecha relación con la nueva función de los usuarios:

- fiabilidad de los contenidos online;

- enlaces;

- control editorial de los contenidos potencialmente dañinos o nocivos.

Ward (2011) va más allá, y apunta que "el reto es mucho más profundo que el debate sobre uno u otro principio deontológico, como la objetividad" y precisa de una reflexión global sobre qué puede hacer la ética "en una profesión que debe proveer de información y análisis al instante" (2011, p. 208).

A pesar de la necesidad que ha expresado un buen número de teóricos y periodistas, de ajustar los valores y códigos éticos de la profesión al contexto digital, cabe destacar que los textos sobre la autorregulación del ejercicio profesional no se han adaptado a dicha demanda y continúan careciendo en su mayor parte de referencias explícitas al ámbito digital.

A este respecto, Díaz-Campo y Segado-Boj (2015) determinaron que sólo 9 de los 99 códigos deontológicos internacionales analizados contienen menciones específicas a cuestiones éticas relacionadas con las tecnologías de la información y la comunicación. Se trata de los códigos de Bosnia-Herzegovina, Canadá, Holanda, Hungría, Luxemburgo, Noruega, Polonia, Rumanía y Reino Unido. Es decir, según este estudio, el $91 \%$ de los códigos mundiales de ética periodística carecen de referencias al nuevo escenario digital. La proporción es aún menor si se tenían en cuenta los problemas derivados por los contenidos de los usuarios, que sólo aparecían en tres códigos: Canadá, Holanda y Noruega.

No es difícil concluir que los medios de comunicación y sus profesionales se enfrentan al ecosistema digital sin unas guías claras de cómo gestionar la nueva realidad, incidiendo consecuentemente en la calidad de su ejercicio. Si se cuestiona a los propios periodistas acerca de los principales problemas que aquejan a la profesión, son mayoría los que apuntan al nuevo entorno digital como caldo de cultivo de dilemas de difícil resolución.

A este respecto, tras un proyecto de I+D+i titulado Los desafíos éticos del periodismo digital. Un análisis comparativo entre tres países europeos: España, Italia y Bélgica, se glosa una serie de factores de diversa índole que pueden influir en el ejercicio ético de la profesión. Su impacto se apoya en una encuesta realizada a 663 periodistas de los tres países mencionados. En la encuesta se otorga una destacada importancia a los factores tecnológicos que han modificado algunos de los hábitos reproducidos en las redacciones de los medios con la irrupción del proceso de digitalización. Entre ellos, la inmediatez a la que impele la información online y las consecuentes dificultades para su verificación y seguimiento, la actualización constante de contenidos y la obsesión por generar tráfico en las noticias. De hecho, en torno a la mitad de los periodistas encuestados cree que las tecnologías digitales influyen de forma notoria en el comportamiento ético de los periodistas (Suárez-Villegas; CruzÁlvarez, 2016).

Uno de los errores más frecuentes es la falta de verificación exhaustiva de los datos ofrecidos, fruto de la ausencia de autentificación de las fuentes seleccionadas

\subsection{La inmediatez informativa como falla deontológica}

Existe cierta unanimidad en señalar la instantaneidad informativa a la que se insta a los profesionales en sus rutinas como uno de los principales problemas asociados a la convergencia periodística digital. Además de la acumulación de roles laborales en una figura de identidad "liquida" que algunos han denominado como "periodista-orquesta", éste se ve sometido a una presión constante por informar en el menor tiempo posible sobre los hechos de actualidad, aprovechando la fugacidad de transmisión facilitada por las herramientas tecnológicas (Karlsson, 2011).

En un entorno mediático fuertemente competitivo en el que ya no sólo participan los medios de comunicación profesionales, la inmediatez supone un requisito estratégico central para hacer periodismo. No obstante, esta realidad conlleva no pocos dilemas éticos. "La carrera por ser el primero en dar una noticia motiva la difusión de errores y prácticas desdeñables como la publicación de imágenes manipuladas o la emisión de noticias sin contrastar" (Micó et al., 2008, p. 17), alterando la percepción y gestión de los valores inherentes a la profesión apuntados anteriormente.

Un periodista con prisas tiene más posibilidades de errar en alguno de los procesos de construcción de la noticia por una mera cuestión de tiempo. Entre estos errores suelen ser frecuentes:

- falta de verificación exhaustiva de los datos ofrecidos (desde hipervínculos adheridos a la noticia hasta información sustancial), fruto al mismo tiempo de la ausencia de mecanismos de autentificación de las fuentes seleccionadas, que suelen provenir cada vez más de perfiles digitales;

- violación de los derechos personales de terceras personas; 
- difusión de información filtrada;

- falta de precisión;

- composición de noticias banales sin un valor social claro;

- actualización constante a la que se ve sujeta la información, dando lugar a una versión nunca acabada de la noticia en sí en la que los posibles errores son subsanados sin apercibir al lector.

El impacto desencadenado por la tendencia a la instantaneidad informativa, debida en parte a la irrupción de las redes sociales en el discurso periodístico, incide de forma directa en la calidad del ejercicio profesional y en la consideración ética del mismo.

\section{En el ámbito digital los problemas éticos} se amplifican, pues el periodista se enfrenta a una dinámica informativa que le obliga a tomar decisiones con mayor rapidez y con efectos imprevisibles por el carácter viral de la información

Los valores éticos del periodismo se mantienen. La raíz del derecho a la información de los ciudadanos se fundamenta en los siguientes principios:

1) Interés público y veracidad de los contenidos: entendiendo por veracidad un procedimiento que asegure una búsqueda diligente que se acerque a la verdad sustancial de los acontecimientos, lo que no excluye posibles errores informativos, pero sí actitudes desaprensivas que concedan a simple rumores naturaleza de noticia.

2) Honestidad en la opinión: ofreciendo la versión más apropiada sobre los acontecimientos desde las claves interpretativas más pertinentes para entender sus razones. La libertad de expresión puede ser tan amplia como se estime oportuna, pero no justifica el insulto o formas irresponsables de vejar la dignidad o la imagen de colectivos sociales.

3) Respeto a los derechos de las personas: evitando intromisiones en asuntos que conciernen exclusivamente a su vida privada, con comentarios vejatorios hacia su persona o un uso de su imagen que le conceda un protagonismo injustificado.

4) Independencia del periodista con respeto a cualquier forma de presión que pretenda influir en su labor informativa con el propósito de atender otros intereses no informativos, por ejemplo, comerciales o publicitarios.

5) Escuchar a la ciudadanía: adoptar dinámicas informativas que favorezcan un debate constructivo con los ciudadanos. La comunicación es una labor colaborativa pero el periodista no debe olvidar su función profesional que concede credibilidad a sus informaciones fundadas en el rigor y su deber de administrar el derecho de los ciudadanos a ser informados.

En el ámbito digital los problemas éticos se amplifican, pues el periodista se enfrenta a una dinámica informativa que le obliga a tomar decisiones con mayor rapidez y cuyos efectos pueden resultar imprevisibles por el carácter viral e inmediato de la información. Por eso, el periodista debería:
- ante la duda, abstenerse de dar informaciones que no hayan sido suficientemente verificadas por las fuentes, más aún en redes sociales (Bruno, 2010);

- centrar su objetivo más en informar bien que en informar con prontitud y con frecuencia con precipitación;

- pensar en los posibles efectos de las noticias, pues un mal tratamiento informativo puede producir perjuicios irreparables por la inmediatez de la noticia (Suárez-Villegas, 2015).

La ética del profesional es imprescindible como un criterio de calidad de una información respetuosa de la verdad y de los derechos de los ciudadanos.

Las pautas que proponemos han sido elaboradas a partir de las recomendaciones de los periodistas entrevistados en España, Italia y Bélgica para el proyecto de investigación citado anteriormente sobre un análisis comparativo de la ética del periodismo digital en tres países europeos. Se trató de un proyecto de tres años, en el cual llevamos a cabo tanto técnica cuantitativa, de una encuesta con preguntas cerradas, sobre nuevas pautas exigidas en la dinámica periodística online, como mediante entrevistas a profesionales con una experiencia de más de dos años en medios digitales. Para la presente propuesta se han elegido las cuestiones más reiteradas por el conjunto de periodistas entrevistados. Indicamos el porcentaje de frecuencia de cada uno de ellos:

- planteamientos honestos y veraces: $90 \%$

- compromiso con las prácticas adoptadas por la empresa: $61 \%$

- verificación responsable de noticias y links incluidos: 74\%

- respeto a la intimidad en las redes sociales: $52 \%$

- conocimiento especializado: $57 \%$

- filtrado de comentarios: $69 \%$

- rectificación: $86 \%$

- derecho al olvido: $79 \%$

- separación información y contenidos promocionales: 54\% - protección colectivos vulnerables: 81\%

Estas propuestas están en línea con las aportaciones señaladas en otras investigaciones (Whitehouse; 2010; Ward; Wasserman, 2010; Ure, 2013) y de las que se vienen haciendo eco también los códigos internos de medios de comunicación (EFE, 2011; BBC, 2011; Reuters, 2012; Washington Post, 2011).

La marca personal del periodista se ha convertido en el principal criterio para la confianza de los ciudadanos en la información

\section{Propuesta de pautas deontológicas para el periodismo digital}

1) El periodista ha de ser congruente en sus posiciones como profesional dentro del medio para el que trabaja y en los usos informativos que pueda ejercer en sus perfiles en redes sociales $u$ otras vías privadas de información. Éstas han permitido un acceso directo a los profesionales de la información, por lo que los usuarios reclaman un compromiso ético inquebrantable entre sus posiciones privadas y 
públicas en su responsabilidad informativa. La marca personal del periodista se ha convertido en el principal criterio para la confianza de los ciudadanos en la información.

2) El periodista que ejerce la profesión dentro de un medio de comunicación deberá adecuar su labor en las redes sociales con sus compromisos laborales, de manera que contribuya a difundir las noticias, pero sin adelantar un tratamiento extenso que pueda convertirse en un perjuicio para el propio medio para el que trabaja. El respeto a los criterios internos adoptados por la empresa para garantizar una información completa y bajo su responsabilidad editorial constituye también una señal de lealtad con su labor profesional.

\section{Se deben rectificar aquellas noticias o} imágenes que puedan inducir a interpretaciones confusas de los acontecimientos

3) Para contrarrestar los efectos de la inmediatez sobre la credibilidad de la información, el periodista deberá siempre verificar tanto el contenido de su información como la inserción de hipervínculos en los artículos hacia sitios insuficientemente verificados. Deberá en cualquier caso corregir posibles errores o informaciones imprecisas que puedan derivarse del imperativo de una inmediatez informativa.

4) El periodista deberá mantener una actitud prudente en relación con la información que pueda obtener en las redes sociales.

- La información contenida en las redes sociales pertenece moralmente a la persona, con independencia de que esté disponible para terceros. Por eso, cualquier uso que se haga de la misma fuera de la propia red social debería recabar el consentimiento de su titular.

- En aquellos perfiles que no estén abiertos al público, el periodista debería evitar recurrir a identidades falsas o contactos de terceros para obtener informaciones o imágenes preservadas por su autor para el dominio de su red de contactos.

- El periodista habrá de procurar en cualquier caso la menor erosión de los derechos de las personas, utilizando exclusivamente aquellos recursos que sean más pertinentes para el contexto informativo, evitando que puedan ser difundidas la exposición de otras circunstancias de la vida privada de las personas o imágenes llamativas.

5) El periodista debe procurar desarrollar un conocimiento amplio de los ámbitos en los que se desarrolla su labor informativa para apreciar su importancia y contar lo importante frente a la novedad que surge de una dinámica informativa marcada por la instantaneidad y la interactividad. Se han de evitar precipitaciones que le conviertan en transmisor de noticias erróneas.

6) El periodista o el medio de comunicación han de procurar que los espacios de comentarios no sean utilizados para expresar insultos y textos vejatorios contra los derechos de las personas. Los mismos límites de la libertad de expresión han de ser también requeridos en la participación de los ciu- dadanos, pues la grosería y actitudes de desprecio no aportan nada al debate público.

7) Se deben rectificar aquellas noticias o imágenes que puedan inducir a interpretaciones confusas de los acontecimientos, priorizando la verdad frente al sensacionalismo y lo espectacular. Se prestará especial cuidado a las imágenes o vídeos en los que puedan ser reconocidas personas y que no guarden una relación suficientemente justificada con los acontecimientos.

8) El periodista respetará el derecho al olvido como una expresión básica de la intimidad de las personas. Con este propósito, no utilizara informaciones halladas en internet sobre la vida pasada de una persona con fines espurios de manchar su dignidad cuando sean episodios de los que haya sido rehabilitado o haya pagado por faltas o sanciones. El respeto a la intimidad abarca también el respeto al control de la propia memoria de lo vivido y el derecho a autorizar o no su conocimiento a terceras personas. El periodista debería mostrar una actitud ética de respeto a la intimidad de las personas y más allá de las decisiones judiciales sobre la disponibilidad o no de ciertos contenidos en los motores de búsqueda.

9) En un contexto en el que los formatos y contenidos resultan más difusos, se debe advertir de manera clara cuándo hay intereses informativos o promocionales en el tratamiento de las noticias, con el objetivo de evitar que la reputación profesional del periodista sea utilizada con intenciones publicitarias o comerciales de las que no queden claramente advertidos los destinatarios.

10) El periodista debe ser responsable de los posibles efectos que se puedan derivar de sus discursos sobre los colectivos más vulnerables, evitando generalizaciones y asociaciones que puedan fomentar estereotipos peyorativos y actitudes discriminatorias.

\section{El periodista respetará el derecho al olvi- do como una expresión básica de la inti- midad de las personas}

\section{Agradecimientos}

Este artículo ha sido elaborado dentro del Proyecto del Plan Nacional de $\mathrm{I}+\mathrm{D}+\mathrm{i}$ del Ministerio de Economía y Competitividad del Gobierno de España con referencia CSO201126620: Desafíos éticos en el periodismo digital. Análisis comparativo entre cinco países europeos para el período 2012-2014. Con posterioridad es aceptada por dicho Ministerio la modificación de la investigación para llevarla a cabo en tres países en vez de cinco, justificada por la reducción del presupuesto solicitado para dicha investigación.

\section{Bibliografía}

Anderson, Chris W.; Bell, Emily; Shirky, Clay (2012). Postindustrial journalism: Adapting to the present. USA. The Tow Center.

http://towcenter.org/research/post-industrial-journalismadapting-to-the-present-2 
$B B C$ (2011). News: Social media guidance. http://bbc.in/nGIxiU

Bruno, Nicola (2010). Tweet first, verify later? Reuters Institute for the Study of Journalism. University of Oxford.

Bruns, Axel (2005). Gatewatching, collaborative online news production. New York: Peter Lang. ISBN: 0820474320

Castells, Manuel (2008). Comunicación y poder. Alianza. ISBN: 9788420684994

Deuze, Mark (2008). "The professional identity of journalists in the context of convergence culture". Observatorio, v. 2, n. 4, 103-117.

http://obs.obercom.pt/index.php/obs/article/view/216

Diakopoulos, Nicholas; Koliska, Michael (2016). “Algorithmic transparency in the news media". Digital journalism. https://goo.gl/wya3Mi

https://doi.org/10.1080/21670811.2016.1208053

Díaz-Campo, Jesús; Segado-Boj, Francisco (2015). “Journalism ethics in a digital environment: How journalistic codes of ethics have been adapted to the Internet and ICTs in countries around the world". Telematics and informatics, v. 32, n. 4, pp. 735-774.

http://reunir.unir.net/handle/123456789/2826?show=full https://doi.org/10.1016/j.tele.2015.03.004

EFE (2011). Guía para empleados de EFE en redes sociales. https://es.scribd.com/fullscreen/77171798?access_ key=key-1vdnglsorj4jf84ctqmg

Hayes, Arthur; Singer, Jane B.; Ceppos, Jerry (2007). "Shifting roles, enduring values: The credible journalist in a digital age". Journal of mass media ethics, v. 22, n. 4, pp. 262-279. https://doi.org/10.1080/08900520701583545

Karlsson, Michael (2011). "The immediacy of online news, the visibility of journalistic processes and a restructuring of journalistic authority". Journalism, v. 12, n. 3.

https://doi.org/10.1177/1464884910388223

Lievrouw, Leah; Livingstone, Sonia (2002). "Introduction: The social shaping and consequences of ICTs". En: Lievrouw, Leah; Livingstone, Sonia (eds.), The handbook of new media. London: Sage, pp. 1-15. ISBN: 0761965106

Micó, Josep-Lluís; Canavilhas, João; Masip, Pere; Ruiz, Carles (2008). "La ética en el ejercicio del periodismo: credibilidad y autorregulación en la era del periodismo en internet". Estudos em comunicação, n. 4, pp. 15-39.

http://www.ec.ubi.pt/ec/04/pdf/02-Jose-Lluis-Mico-Laetica-en-el-ejercicio-del-periodismo.pdf
Mitchell, Bill; Mann, Fred (2002). “'New media' bring a new set of problems". Poynter, 12 August.

http://www.poynter.org/uncategorized/1734/new-mediabring-a-new-set-of-problems

Purcell, Kristen; Rainie, Lee; Mitchell, Amy; Rosenstiel, Tom; Olmstead, Kenny (2010). Understanding the participatory news consumer. Pew Internet \& American Life Project. https://goo.gl/KYyUyQ

Reuters (2012). Reporting from the internet and using social media. Handbook of journalism. Reuters.

http://bit.ly/YIN6G9

Said-Hung, Elías (2010). TIC's, comunicación y periodismo digital, v. II. Universidad del Norte, Barranquilla.

Suárez-Villegas, Juan-Carlos (2015). “Nuevas tecnologías y deontología periodística: comparación entre medios tradicionales y nativos digitales". El profesional de la información, v. 24, n. 4, pp. 390-395.

https://doi.org/10.3145/epi.2015.jul.05

Suárez-Villegas, Juan-Carlos; Cruz-Álvarez, Jesús (2016). "The ethical dilemmas of using social networks as information sources. Analysis of the opinion of journalists from three countries". Revista latina de comunicación social, v. 71, pp. 66-84.

http://www.revistalatinacs.org/071/paper/1084/04en.html

Ure, Mariano (2013). “Dilemas éticos y modelos deontológicos para el periodista usuario de medios sociales". Cuadernos.info, n. 32, pp. 67-76.

https://doi.org/10.7764/cdi.32.492

Ward, Stephen J. A. (2011). Ethics and the media. Cambridge University Press. ISBN: 9780521718165

Ward, Stephen J. A.; Wasserman, Herman (2010). "Towards an open ethics: Implications of new media platforms for global ethics discourse". Journal of mass media ethics, v. 25, n. 4, pp. 275-292.

http://dx.doi.org/10.1080/08900523.2010.512825

Washington Post (2011). Digital publishing guidelines: Social media.

http://www.washingtonpost.com/wp-srv/guidelines

Whitehouse, Ginny (2010). “Newsgathering and privacy: Expanding ethics codes to reflect change in the digital media age". Journal of mass media ethics, v. 25, n. 4, pp. 310-327. https://pdfs.semanticscholar.org/7770/56fad337da7a51a3 710143c6defb799d04f1.pdf https://doi.org/10.1080/08900523.2010.512827 